\title{
Translation Product: How is it Assessed by the Trainees, the Trainers and the Employers?
}

https://doi.org/10.33806/ijaes2000.19.2.4

\author{
Ogareet Yacoub Khoury \\ Al-Ahliyya Amman University, Jordan
}

\begin{abstract}
According to Koby (2014), translation assessment for pedagogical implications needs to be investigated further. This paper discusses how translations of university senior students in the Jordanian context are assessed by university translation teachers, employers in the translation labour market and by the students themselves. It probes into the assessment criteria employed by the teachers and the employers for pedagogical implications. Teachers and students were sampled from five different universities in Jordan while the employers were sampled from translation service providers Amman. Twenty six senior students were requested to perform a task of inverse translation to be assessed by the three groups of assessors. The teachers and the employers were asked to rate the product on a five-point scale and comment on the errors and deficiencies that are considered crucial from their perspective. In addition, they were requested to elaborate on the assessment criteria they used. Students, on the other hand, had to respond to a selfcriterion rating scale. The results show that there was a high level of concurrence in the assessment of the teachers and the employers and a disjunction between that and the selfassessment where the latter showed some over-estimation in comparison with the second party assessment.
\end{abstract}

Keywords: extra-linguistic, instrumental competence, psycho-physiological components

\section{Introduction and theoretical framework}

Despite its limitations in evaluating the overall competence, product assessment has always been considered as one main effective tool in revealing several aspects of competence. As Darwish (1999) states, "the translator competence is always called into question whenever the quality of the translation product is questioned" (1999: 1). Similarly, Campbell (1998) argues that "the assessment of translation quality is best seen as a matter of profiling the competence of learners, rather than simple measuring of the quality of their output" (1998: 163).

\subsection{Product-oriented studies}

It is essential to clarify that product assessment in general involves different types of evaluation carried out for different purposes. According to Hurtado Albir and Melis (2001), three types of translation assessment can be identified: 1) evaluation of published translations, 2) evaluation in professional translation practice and 3) evaluation in translation teaching for pedagogical purposes. According to the authors, evaluation of published translations refers to the 
evaluation of a translation of a literary or a sacred text to discuss its merits and demerits or to propose solutions; i.e. translation criticism. Hewson (2011) points out that the aim of translation criticism is not to judge a given translation or the competence of the translator as much as it is to understand where the target text stands in relation to its original. The second type of evaluation is the one the present paper is concerned with. It is defined as evaluation of the competence of a given translator for professional reasons such as applying for a post. It was called by a group of researchers named PACTE (Procés d'Adquisició de la Competència Traductora i Avaluació) as "competence in written translation" (2003: 3) since the quality of the translation reflects some aspects of the competence of the translator. Such assessment is more often than not conducted by translation teachers when evaluating the development of their trainees by the end of a translation course as well as by employers to evaluate the competence of job candidates. The third type is basically carried out in diagnostic testing conducted at the beginning of a translation course for pedagogical purposes and is often called formative testing (Colina 2003).

The product-oriented studies carried out by PACTE (2005, 2009 and 2011) proved that several aspects of translation competence can be inferred from the product. The main competences identified by PACTE are the 1) bilingual subcompetence which is the knowledge required to communicate in the two languages, 2) The extra-linguistic competence that includes the bi-cultural knowledge, encyclopaedic and subject knowledge, 3) The instrumental competence which is the ability to use documentation sources and information technologies, 4) knowledge about translation which refers to knowledge about translation processes, methods and procedures as well as the aspects of the profession and 5) The strategic competence that is the central competence involving the ability to solve the translational problems effectively and efficiently. In addition, the model (2011) considered some psycho-physiological components including memory, perception, attention, intellectual curiosity, motivation as supporting factors for translation competence. The analysis of the results of the present paper is basically conducted in light of the main competences highlighted in the model developed by PACTE (2011).

\subsubsection{Second party assessment}

Investigating the product for competence-oriented research was reflected in some previous studies such as the one conducted by Stansfield et al. (1992). The sample of the study was made up of FBI employees who were asked to perform tasks in both direct and inverse translation. The purpose of the assessment -which was basically carried out by the researchers- was to reveal aspects of the abilities of the subjects and validate their job-related tests. The study, which was linguistically oriented, showed that subjects performed better on the accuracy scale (transfer of content) from L1 to L2 and better on the expression scale (linguistic features) from L2 to L1.

Within the Arab context, there were some studies which tended to investigate translations of specialized texts like the one conducted by Abdel- 
Hafiz (2002) on journalistic texts and the one conducted by Al-Najjar (2011) on legal texts. In his corpus-based study, Abdel-hafiz (2002) investigated translations of English journalistic texts into standard Arabic. The results revealed that the most common deficiencies were attributed to inappropriate selection of the TL equivalent in addition to a reflection of stylistic errors. The study conducted by Al Najjar (2011) focused on legal translations of trainees from Arabic into English. Similarly, it also reflected lexical-semantic, stylistic and grammatical errors in addition to poor abilities in searching and researching. These included mistranslation, comprehension-related errors, absence of the modal verb shall, wrong usage of tenses and subject-verb agreement. However, the study was conducted on a group of sentences rather than a text where several textual aspects could not be detected and thus was not a competence investigation as such.

In addition to the fact that product assessment for competence evaluation needs to be investigated further, the studies referred to previously belong to the conventional mode of product assessment research. Such product assessment research merely involves two main parties; the researcher and the subjects whereby the former evaluates the latter based on pre-set assessment criteria adopted for research purposes.

However, there are other modes of similar research in which the researcher could play the role of a mediator between the sampled subjects and some experienced evaluators who are actual role players in translation teaching or the translation industry. Those assessors could be teachers or peers from the academia as well as employers, professional translators or clients from the translation industry. In such product-oriented studies, the role of the researcher would be limited to investigating and analysing perceptions of competence or the assessment methodology employed by the assessors. A good example of this type of studies is the empirical research conducted by Waddington (2001) which sampled teachers from 20 different European and Canadian universities to assess inverse translations performed by translation students. Although it touched on competence of students, the main purpose of the study was to reveal the assessment methods applied by translation teachers and determine the validity and reliability of their evaluation methods. The figures revealed that $38.5 \%$ used a holistic method based on grading criteria. Similarly, the study carried out at Shiraz University by Riazi and Davoodi (2008) investigated the assessment methods applied by university teachers showing that almost all teachers assessed translation products on ad hoc basis without relying on any criteria or grading scales. However, the study reflected nothing about the competence of the performers. In the translation industry, some studies were conducted to investigate the assessment criteria employed by professionals in the industry (e.g. Orlando 2011) which revealed that the majority of the translation agencies tend to assess the translation product objectively along with some subjective considerations of the evaluators. 


\subsubsection{Self-assessment}

The involvement of trainees in the assessment of their own translations is even less common in this type of research. Hidayat (2013) conducted a study in translation product assessment in which teacher, peer and self-assessments were investigated in relation to each other. It revealed that students over-estimated their translations by giving themselves higher marks than those given to them by their peers and teachers. To guide trainees in any given self-assessment process, a few self-assessment rating scales were developed. The one designed by Robinson et al. (2006) could either be used by students in an actual translator training context or employed as an assessment tool in empirical studies as is the case in the present study.

By reviewing the studies mentioned above -which involved actual stakeholders- it can be noticed that each study reflects one or more missing aspects. They either focused on the assessment methodology without touching on the competence of the translators or tackled competence from one perspective and missed triangulating different perspectives. The present paper triangulates its methodology by investigating how a given translation product is perceived in terms of competence and evaluated by different stakeholders; namely, the students, the teachers and the employers.

\section{Research questions}

The present paper was mainly concerned with answering the following research questions in relation to the perspectives of the students, the teachers and the employers in assessing a given translation product:

1. How are the written translations of trainees rated and marked by university teachers and employers and what are the assessment criteria employed?

2. What types of deficiencies and errors are considered crucial for the teachers and employers in evaluating competence?

3. What type of translation could be perceived good enough by the employer(s) to consider the translator(s) for a job?

4. How are written translations self-assessed by the students/ trainees?

5. What quality of a translation do employers believe can qualify a candidate for a job in the labour market?

\section{Limitation of the study}

Despite the insights the present study provides into translation competence, one limitation could be the infeasibility of generalization. This is due to two main reasons. Firstly, the sample included in the experimental task is relatively small in comparison with quantitative studies. Secondly, the results of this qualitative study are based on assessments of a specialized text into English. Whether the same results can be reflected if the students were required to translate a less specialized text into their first language or not remains an open question.

\section{Methodology}

In order to answer the stated research questions, a selected sample of senior students were requested to translate a text whereby each translation had to be self- 
assessed by the student herself/ himself as well as by one teacher and one employer. This assessment included a general rating and marking of each translation by each assessor in addition to a deep reflection on the terminology, vocabulary, orientation to the genre of the target text as well as the structure of the translation. The following sections provide further details on the nature of the sample, the data collection instruments and the analysis methodology.

\subsection{The sample}

Out of the thirteen BA and MA translator training programs in Jordan, ten undergraduate programs are offered by private universities and five of these are located in the capital city, Amman. For a narrowed and focused study, the sample was only selected from the five private universities in Amman; namely, Ahliyya, Applied Sciences, Petra, Zaytoonah and Isra private universities. Twenty six male and female translation senior students were asked to perform inverse translation from Arabic into English of a legal text (Appendix 1) and assess their own translations by responding to multiple choice items in an assessment form; i.e. closed-ended questionnaire (appendix 2). In addition, nine teachers from the same private universities and seven employers from several translation service providers (second party assessors) were selected to assess the translations by responding to different assessment forms; i.e. closed and open-ended questionnaires (appendices 3 and 4). Therefore, each translation was assessed by the performer of the translation as well as by one teacher and one employer in order to triangulate the results by investigating three different perspectives and assessment methodologies of the same product.

\subsection{The experimental task}

The experimental task involved a translation of a legal text from Arabic into English (The selection of the source text -which is an authentic text- was based on the results of a pilot study conducted on the type of texts and the translation direction required the most in the translation market). The use of online and paper dictionaries/ sources was allowed. Students were required to perform the translational task and respond to a criterion-referenced rating scales as a selfassessment form. The teachers and employers were asked to assess the translations by responding to open and closed-ended assessment forms.

\subsection{Data collection and analysis instruments}

Quantitative data consisted of:

1. The second party rating of the quality of each translation on a five-point scale from Excellent to Poor presented in the actual rating of each translation separately and the mean score of all the responses.

2. The second party marking -out of ten- of each translation on a three-point scale (below 5: fail mark, 5-7: pass/ lower range or 8-10: pass/ higher range) presented in the actual mark of each translation separately and the mean score of all the responses. 
3. The marks scored by the students through their selection of one out of six answer options in evaluating each area; i.e. comprehension of the ST, choice of terminology and the structure of the TT). The self-assessment form used was an adapted version of the criterion-referenced rating scale suggested by Robinson et al. (2006). Each qualitative descriptor for each answer option is assigned a predetermined range of marks out of ten. The marking scale is as follows ( $a=$ zero mark, $b=1-2$ marks, $c=3-4$ marks, $d=5-6$ marks, $e=7-8$ marks and $\mathrm{f}=9-10$ marks). The median of each mark range is given for the respective answer option for each of the three categories (comprehension, terminology and structure). The total mark scored for each translation is calculated by adding and dividing the three medians of the three categories. For simpler presentation of the marks, they were categorized within a wider range; i.e. below 5: fail mark, 5-7: pass mark/ lower range and 8-10: pass mark/ higher range in order to be comparable with the marking of the second party assessors.

4. The ratio of Yes: No on the possibility of being employed based on the quality of the translated texts -as provided by the employers and the students themselves. Qualitative data consisted of:

1. Open responses on the deficiencies found in the translations and the assessment criteria -as provided by the second party assessors.

2. Audio-recorded post-task focus group discussions in which the students reflected openly on the task.

\section{Data presentation and analysis}

\subsection{Assessment criteria}

To understand the approach employed by the second party assessors, they were required to elaborate on the criteria or the grading scale they normally adopt in a regular translation assessment. Responses received to this open-ended item revealed that few assessors applied some generic assessment criteria or error counting revealing their marking strategy rather than adhering to a pre-set rating scale. The rest did not clarify any assessment criteria which reflected a mode of assessment on ad hoc basis. The criteria clarified by the teachers were split from those clarified by the employers as follows.

\subsubsection{Criteria used by teachers}

With reference to the reflections of the nine teachers who took part in the assessment from the five universities, three teachers (one from Petra University and two from Zaytoonah University) clarified their personal assessment criteria or grading strategies. The following quotes of the teachers revealed that holistic assessment criteria were employed by two teachers while error counting was used by one.

Teacher 1: "The text is evaluated according to the lexical choices, terminology, word order, punctuation, spelling, grammar, cohesion and coherence." (Zaytoonah University).

Teacher 2: "35\% structure, $35 \%$ terminology and $30 \%$ for the orientation to the target text type" (Petra University). 
Teacher 3: "Here at the department, we do not have any common grading criteria. I personally count the errors and deduct grades accordingly" (Zaytoonah University).

The different responses provided by the teachers evidently revealed that there is an absence of common pre-determined criteria or rating scales adopted at the translation departments in the respective universities. Some teachers did not refer to any criteria such as the teachers of Ahliyya, Applied Science and Isra universities. Other teachers referred to different assessment strategies within the same university as was the case with the two teachers from Zaytoonah University in which one referred to very generic criteria and the other one used error counting. Even teacher 2 of Petra University who clarified the weight given to each aspect was found to reflect a personal grading strategy as the other teacher involved in the assessment from the same university did not mention any specific criteria. Therefore, the responses showed that there was a personal employment of holistic assessment with some further clarification of the grading strategy as evident in the responses of teacher 1 and teacher 2 and an error counting strategy by teacher 3 .

The results above comply with the findings of Riazi and Davoodi (2008) which revealed that most teachers use holistic ad hoc assessment at Iran universities. Similarly, this was found to be the practice of some teachers in the study conducted by Waddington (2001) at Canadian and European universities. The absence of assessment criteria in the assessment of the teachers means that students are not given the chance to understand how their translations are assessed which normally results in a poor ability to perform a self-assessment and hence a probable disjunction with a second party assessment.

\subsubsection{Criteria used by employers}

As was the case with the teachers, the employers did not reveal any employment of grading scales but rather reflected generic criteria, error counting in addition to ad hoc assessments as shown in the following quotes provided by the employers:.

Employer 1: "We need to investigate the following: Does the translation carry all the ideas of the original? Does the translation make explicit what is implicit or unclear? Does the translation capture the style of the original text?"

Employer 2: "We normally count errors of all types; structural, terminological, overall cohesion of the text in which $1 / 4$ a mark is deducted for each error. Applicants whose translations reflect serious errors such as subject-verb agreement, word order, capitalizations, word-for-word translation or evidence of using Google Translate are normally eliminated."

Employer 3: "We do not have any specific criteria for evaluation; it all depends on the view of the assessors who normally have a long experience in evaluating translations of applicants."

The feedback of the employers on the criteria reflected a similar mode of assessment to that of the teachers. There was no mentioning of any rating scales. It was either an error counting method or very generic criteria or even ad hoc subjective assessment as stated by employer 3 . The practice of error typology identified by employer 2- with associated penalties and deductions was found to 
be one of the most common methods used in the translation industry (O'Brien 2012).

The data collected from the teachers and the employers generally reveal that there is an absence of common specific criteria, in particular rating scales, by which the assessor could be guided. This was referred to as subjective, intuitive evaluation (House 2001). After elaborating on the assessment criteria, the second party assessors were asked to reflect on the quality of the translation by identifying the errors and deficiencies that were considered crucial from their perspectives. The second party assessment along with the responses of the students in the criterion-referenced rating scale are all integrated within the indepth qualitative assessment.

\subsection{Overall assessment and rating}

The answer options of the students were associated with their respective marks. The marking of the comprehension of the ST, the choice of terminology and the structure of the TT were added and divided by three to get the total mark for the whole translation for each student. The second party assessors rated the translations by selecting an option on a five-point scale (excellent, very good, good, acceptable, poor) and marked the whole translation on a three-point scale (below 5: fail mark, 5-7: pass mark/ lower range and 8-10: pass mark/ higher range).

The results revealed a trend of dissatisfaction among the second party assessors with the overall quality of the translated texts while the students seemed to be generally satisfied with their performance. Out of the 26 translations, the ratio of pass to fail marks [Pass: Fail] was [23:3] according to the scoring of the students, [10:16] according to the assessment of the teachers and [9:17] according to the assessment of the employers. The assessment reflected a remarkable variation ratio between the marking of the students on the one hand and that of the second party assessors on the other hand. This disjunction is to be discussed along with the rest of the results in the subsequent sections.

The relation between the marking and the rating of the translations by the second party assessors seemed to reflect a certain pattern. It was noticed that poor quality of translation was $100 \%$ associated with a fail mark and good quality was $100 \%$ associated with the mark range 5-7 while acceptable quality of translation lied in the grey area where it was associated with a fail mark in some assessments and a pass mark from 5-7 in others. The rating very good was associated with the mark range 8-10 and appeared once in the assessment of a teacher for one student. None of the translations was assessed as excellent by any of the second party assessors.

\subsection{Who is considered for employment?}

In addition to the rating and the marking of the translations, both the students and the employers reflected on the chances the students stand to be employed based on the quality of their translations. In terms of frequencies, 12 out of the 26 students believed their translations could qualify them for a job in the market. The 
responses of the employers, on the other hand, reflected that only five of the twenty six translations were seen good enough to qualify their translators for a job. The three students who gave themselves fail marks in the self-assessment did not evidently expect themselves to be employed. The rest who scored pass mark according to their assessments were basically divided between those who were certain their translations could qualify them for a job and those who were undecided. Nine of the twelve students who believed their translations could qualify them for a job were perceived by the employers as below the standards required for the job. The types of errors identified by the employers for these translations are discussed in 5.4.1 and 5.4.2.

It can be noticed that there is a clear disjunction in the two perspectives. This could be attributed to little awareness of the quality of the translation that could qualify candidates for a job and little or no awareness of the assessment and employment criteria in the market. The in-depth reflections on the present translations are illustrated below based on the answers received to the open-ended items in the assessment forms.

\subsection{In-depth qualitative assessment}

As requested in the assessment forms, most of the errors identified by the second party assessors were related to the comprehension of the source text, the choice of terminology/vocabulary and the structure of the written expressions and orientation to the target text type/ genre. Hence, feedback was classified within these three broad categories. The feedback of the teachers and employers on each of the categories was directly associated with the answer options selected by the students on the respective category as reflected in tables 5.4.1, 5.4.2 and 5.4.3 below.

\subsubsection{Comprehension of the source text Self-assessment:}

- The answer option (e) was opted for the most (12 out of 26 students) which was associated with the descriptor: My comprehension of the source text was 'very good'.

- The total average mark calculated for the 26 translations based on their choices was $6.4 \approx 6$ out of 10 (pass mark: lower range).

Second party assessment: Despite that the second party assessors were not required to comment on the comprehension of the ST as it could not be easily spotted, three assessors (one teacher and two employers) were able to detect a miscomprehension of some expressions.

\subsubsection{Register, terminology and vocabulary Self-assessment:}

- The answer option (d) was opted for by the majority of students (14 out of 26) which was associated with the descriptor: My choice of 
register is mostly appropriate for the legal text and mostly consistent throughout the translation and the choice of vocabulary and terminology is effective and appropriate despite some mistakes and occasional errors

- The total average mark calculated for the 26 translations based on their vocabulary and terminological choices is $5.5 \approx 6$ (Pass mark: lower range) which was lower than the mark obtained for comprehension of ST,

Second party assessment: The comments and errors identified by the second party assessors, which were grouped within categories, were integrated and summarized as follows:

Vocabulary/ Terminology:

- Wrong usage of expressions/ terms or inappropriate lexical choices.

- Usage of incorrect/ non-existing vocabulary.

- Unawareness of legal terminology/ poor legal terminology.

Register/ Orientation:

- Inappropriate choice of terms for legal register.

- Unfamiliarity with legal discourse/ absence of 'shall' and other terms such as thereof and hereto.

- Absence of legal sense such as the absence of passive voice.

- Literal or unnatural translations.

- Poor command of English.

Semantic remarks:

- Mistranslations that are reflected in poor ability to pick up the appropriate equivalent.

- Redundancy, e.g., picking up more than one equivalent for the same lexical item.

- Shift of meaning resulting in a translation that does not convey the meaning.

- Unnecessary additions/ and/or omissions.

Other:

- Reflection of stylistic shift.

- Poor readability of the target text.

- Miscomprehension of the ST.

- Use of Google Translate or use of Google Translate without postediting.

The assessments above revealed that the teachers and employers identified several terminological errors and register deficiencies that were considered crucial for them in the vast majority of the translations showing a general perception of dissatisfaction. Out of the seven translations which were granted pass marks by both groups of second party assessors, two translations were considered as almost free of crucial lexical-semantic errors. The rest of the translations including those which were granted pass marks were still commented on as reflecting some wrong 
usage of legal terms or absence of orientation to TT genre along with few examples of addition or omission.

Despite the concurrence in the second party assessments, a slight difference was noticed between the assessment attitude of the teachers and that of the employers. The feedback of teachers was found to be more analytical and microoriented while the employers showed a stronger tendency to identify errors in a rather concise way by focusing more on the macro level where the feedback was more holistic than analytical. By way of illustration, the employers generally paid more attention to the overall text in terms of literal and word-for-word translation and the overall legal sense at the textual level. At the macro level, the employers also perceived some translations as an indication of poor command of English. Some employers were specific only in identifying the legal terms that should have been reflected in such a text; they tended to focus not only on the absence of shall but the absence of other legal markers such as thereof, hereto, hereunder, etc. One more aspect of the slight difference between the assessments of the two groups was that the employers -unlike the teachers- were found to provide some encouraging comments for those translations which did not reflect crucial errors. For instance, the assessment of the employers for translations which they had given pass marks included comments such as 'good attempt to maintain the legal sense'; 'with practice, the translator can improve since s/he has good command of English and good knowledge of legal terminology'; 'legal terminology is applied as necessary'; 'best translation among the others or 'the closest to a good translation'. This reflected some consistency between the in-depth assessment and the marks given by the employers. Such comments were absent in all the assessments of teachers including the translations for which the teachers themselves had given pass marks. The teachers were more analytical and errororiented without shedding light on the positive aspects of the lexical-semantic choices. Other than these slight differences, the assessments of the two groups concurred in most areas.

On the other side of the spectrum, some disjunction was observed between the second party assessments on the one hand and the self-assessment on the other hand. For instance, the students who opted for the answer option (e), were those who supposedly believe that their choice of register and vocabulary was appropriate and effective. However, the feedback provided by the second party assessors on some of the same translations revealed that they did not agree on the appropriateness and/ or the effectiveness of the choices made. Some of their comments included non-existing vocabulary, wrong usage of expressions, wrong lexical choices of legal terms, shift of meaning as well as absence of target text orientation. Similarly, the reflections of the teachers and employers on the translations of the students who opted for (d) also revealed a level of disjunction. While this group of students stated that their choices were mostly appropriate and effective, the feedback received from the teachers and the employers identified wrong usage of expressions, absence of target text orientation and excessive use of Google Translate. There was a minority of translations (belonging to five students) which reflected a good extent of concurrence across the three 
assessments in which two were positively assessed and three were negatively assessed by the three groups of assessors.

\subsubsection{Structure of expressions Self-assessment:}

- The answer option (d) was opted for the most (12 out of 26 students) which was associated with the descriptor: The way the expressions are structured is effective but there are errors in the use of articles, prepositions or spelling of less common words in addition to some occasional mistakes in complex structures.

- The total average mark calculated for the 26 translations based on their choices on the structure of the TT was $5.5 \approx 6$ (Pass mark: lower range) which was the same as the mark scored for the lexical-semantic choices.

Second party assessment: The main errors and deficiencies identified can be integrated and summarized as follows:

A) At the word level:

-Wrong usage of word class (verb-noun/ adjective-adverb).

- Wrong usage of prepositions, conjunctions and articles.

-Lack of subject-verb agreement.

- Reflection of missing auxiliaries.

B) Above the word level:

- Poor command of English resulting in vague translations.

- Incorrect, poor or ungrammatical structures.

- Improper word order.

- Lack of cohesion and/or coherence

- Excessive use of adjectival and adverbial clauses.

- Improper punctuation (e.g. unjustified capitalization).

- Reflection of spelling mistakes.

- Use of active voice in cases where passive voice should have been used.

The comments provided above revealed that both groups of assessors shared a common ground in the way the target text was assessed in terms of structure as it was the case in the assessment of register and terminology. However, while the feedback of employers was slightly more concise, macro-oriented and more positive than that of the teachers in the assessment of register and terminology, the assessment of structure reflected a different mode. Both groups of assessors provided micro and macro comments on structure with no significant difference. The encouraging comments provided by the employers in the assessment of terminology and register were not reflected in the assessment of structure and grammar. Therefore, it can be deduced that most of the pass marks granted by the employers were given to the lexical-semantic choices rather than the structure of the written expressions. Most of the translations including those which were given pass marks were still commented on as containing structural deficiencies. 
The disjunction noticed between the self-assessment and the second party assessment of register and terminology was also noticed in the feedback on structure and grammar. This was particularly evident in the assessments of those students who opted for the answer options, f, e and d. The feedback provided by the teachers and employers on the translations of students who opted for these options reflected basic structural errors such as whole broken structures, wrong word order, wrong usage of word class and errors in the subject-verb agreement. Evidently, these mistakes were not only confined to the complex structures as the students assumed.

The in-depth assessment carried out by the three groups of assessors complied with the overall rating and marking. It revealed that the students were generally satisfied with the quality of their translations and the second party assessors were dissatisfied with the vast majority of the translations. This variance in perceptions resulted in a level of disjunction between the selfassessment and the second party assessments giving an indication that the inexperienced students were not fully aware of the source and the nature of the translational problems they faced. Thus, they were unaware of what translation competence is or at least what level of competence trainers and employers expect them to show. This unawareness resulted in a misjudgement of the quality of their translations in comparison with the judgement of the second party assessors. By way of illustration, most of the students stated -in the post-task group discussions (see 6. below) that the translational problems they faced were confined to the structure of the written expressions while the lexical-semantic choices did not constitute a major problem for them since they were able to find their lexical equivalents. The second party assessors, however, identified deficiencies in both the grammatical and the lexical-semantic choices. Two points can be highlighted here. Firstly, the students did not show sufficient awareness of the fact that the lexical-semantic choices are not only limited to finding the TT equivalent -as they seem to think- but have to be appropriate for the context and register. This indicates a tendency towards what is called a 'bottom up approach'. A bottom up approach in translating is reflected when equivalence at the word level is the first element taken into consideration (Baker 1992) or when there is evidence of signoriented translating even of small linguistic structures (Colina 1999). Secondly, almost all students admitted facing difficulties in the structuring of the expressions, yet the majority of them scored pass marks in the structure of the written expressions. This indicates that the translational problems the students believed they had faced in structure were perceived as having been solved eventually. However, from the perspectives of the second party assessors, the translational problems were not properly solved. In other words, even when some translational problems were identified by the students, there still seems to be a misjudgement of whether they were properly solved or not. According to Kiraly (1995), this could be due to a teacher-centred instruction resulting in a suppressed role of trainees in the learning process.

According to PACTE (2000, 2003), any stage prior to competence -which is considered expert knowledge- is a novice stage. Therefore, lacking translation 
competence indicates that the translator is at the novice stage. However, the proficiency scale developed by Sanchez (2007) which is based on the one proposed by Dreyfus and Dreyfus (1986) identified more stages in the development of competence. These comprise: novice, apprentice, competent, proficient and expert. Mapping the type of errors identified by the second party assessments onto the proficiency scale revealed that were basically associated with the novice and apprentice stages in the vast majority of the translations. These included but were not limited to transfer of isolated words and phrases, little language control, inaccurate punctuation, false cognates, obscured meaning, unsatisfactory cohesion, little familiarity with text type conventions, insufficient knowledge of the use documentation sources, inability to detect and solve problems as well as reliance on bottom up processes.

\section{Post-task reflections and competence implications}

The subjects of the task were required to sit for focus group discussions to reflect on the translational problems faced in the process. The group discussions were related to the assessments and perceived in light of the translation competences developed by PACTE (2011) as follows:

1. Difficulty of comprehending and translating the text (bilingual and transfer competences).

The group discussions revealed that the vast majority of the students did not have problems comprehending the source text except for five students who stated that they had some comprehension difficulties. They attributed that to three main reasons: the specialized nature of the text, the fact of not having been exposed to such a text type as well as not being asked previously to translate a legal text into L2. Other students, especially in the groups of Applied Science University and Isra University believed that the difficulty of comprehending the source text was due to some weak structures in the ST which seemed to them a translated text. With reference to 5.4.1 above, it can be noticed that their miscomprehension of ST expressions was clear enough to be detected by the second party assessors.

As for the production of the TT, some responses reflected a level of awareness of the specificity of the register as students gave comments such as 'I was able to structure some written expressions but did not feel they were appropriate for the legal register' or 'I faced difficulty in deciding whether the term I am using is appropriate for the legal text'. The overall feedback of the second party assessors revealed that students had serious difficulty in the lexical semantic as well as the structural- grammatical choices. According to PACTE model, lexical-grammatical knowledge in each language lies in the core of the bilingual and transfer competences.

2. Exposure to similar types of texts/ genres (domain knowledge: an aspect of the extra-linguistic competence).

It was noticed that students across the five universities were divided in their responses into those who had previous exposure to similar types of texts and those who had never dealt with such texts before. The fact that this disagreement was reflected within students of the same university showed that the content and 
material taught in a particular specialized translation course in a given university is not unified but rather left to the instructor. Students of the same university reacted to this by stating 'I have translated texts of a similar nature when I took the course with professor [...] or 'I haven't been exposed to such texts when I had the legal course with professor [...]. In its simplest form, this can be seen as a lack of coordination among teachers in the syllabi of courses.

3. The task of inverse translation (directionality: an aspect of transfer competence) The reflections of students clearly revealed that inverse translation was rarely focused on in the practical courses they had at their universities. They argued that this was one of the factors that added to the difficulty of the task.

4. Submitting the text electronically and sources consulted (instrumental competence)

The students' feedback showed that they had no problem in searching the online sources or processing the text electronically. However, they also revealed that they were rarely asked to do so in the training context. It is worthy of note that Google Translate, as a translation tool was excessively used by no less than two students in each group with a complete reliance in some cases. Other online bilingual dictionaries such as Bing Translator, Maany were also used with less dependence on electronic and paper dictionaries. Moreover, students did not mention consulting any specialized legal dictionaries despite being aware of the specificity of the legal register. Reliance on Google Translate seemed clear enough to be spotted by some second party assessors. Translate without postediting can also be interrelated to the absence of computer-assisted translation in which students could be oriented on the proper usage of online tools. The students stated that they had not been generally encouraged to perform computer-assisted translation. Interestingly, students of Ahliyya University whose study plan reflects a compulsory course of CAT also seemed to have used limited sources that were confined to Google Translate and online general purpose dictionaries such as Bing Translator and Mawrid but not legal specialized dictionaries or online parallel texts.

\section{Conclusion and recommendations}

According to the overall rating and the in-depth assessment carried out by the second party assessors, no significant differences were noticed among the students of the different universities. Both pass and fail marks were distributed almost equally across the five universities. There are only two observations that are worth mentioning in relation to students of Isra and Zaytoonah universities. Firstly, the translations that were considered by the employers as up to the job requirements represented all universities except for Isra University. In addition, it was noticed that most of the macro-level comments on terminology and register were made in relation to translations performed by the students of Zaytoonah and Isra universities. Therefore, there seems to be some indication that students of these two universities show more weaknesses.

In conclusion, the findings revealed that the teachers and the employers were not satisfied with the quality of the vast majority of the translations. The 
deficiencies identified by both groups of assessors reflected basic lexicalsemantic, stylistic, and grammatical errors in most of the translations. Mapping the identified deficiencies onto the PACTE-based model of legal translation developed by Prieto Ramos (2011) and the proficiency scale developed by Sanchez (2007), most senior students were found to be at the novice level in which the main competences seemed to be underdeveloped.

The concurrence in the second party feedback was evident in several aspects. Firstly, the mode of assessment was found to be characterized by the absence of specific criteria. Secondly, both groups of assessors agreed to a great extent on the types of errors and deficiencies identified as well as on the overall rating of the translations. The only slight difference between the assessments of the two groups was that the assessment of the employers reflected some positive, encouraging comments which were absent in the assessment of the teachers.

According to Schaeffner and Adab "translation competence is most effectively developed at an academic institution" (2000: $\mathrm{x}$ ). This does not seem to be the case in the Jordanian context or at least in the sample studied at the private universities. When senior students show a poor level of performance, serious questions need to be raised about the efficiency of the design of the translator training programs at the Jordanian universities.

Most of the errors identified by the assessors were related to language proficiency. This is directly related to the bilingual competence (PACTE 2000) which was the first competence highlighted in the earliest translation competence models, e.g., Harris and Sherwood (1978). In its simplest form this should indicate that language proficiency needs to be ensured.

The following recommendations can be helpful if taken into consideration by the academic institutions when accepting students for a translator training program:

1. Imposing L2 proficiency entry restrictions, e.g., placement exams or introducing an L2 remedial plan for students of low language proficiency. In fact, several studies in the Arab world and Jordan in specific have revealed that the vast majority of school leavers show poor command of English language as university candidates. These studies include but are not limited to the ones conducted by Yousef (2004), Mukattash (2003) and Abu Risha (2011).

2. Ensuring the maximum benefit of the program through appropriate sequencing of courses. There should be full adherence to the correct sequencing of courses. In other words, academic advisors need to ensure that all language pre-requisites are taken before registering any specialized translation courses.

3. Enhancing English for specific purposes courses so that students can deal with highly specialized texts. Within the translation courses, inverse translation needs to be stressed further as it reinforces the ability of students to work into the foreign language which is in more demand than before and is considered more rewarding ((Pavlović 2013). 


\section{Ogareet Khoury}

Department of Translation

Al-Ahliyya Amman University

Jordan

ogareet_khoury@hotmail.com 


\section{References}

Abdel-Hafiz, Ahmed-Sokarno. (2002). 'Problems in translating English journalistic texts in Arabic: Examples from the Arabic version of Newsweek'. International Journal of Arabic-English Studies, 3 (1): 69-94.

Abu Risha, Mohammed. (2011). Towards more efficient courses oftranslation. www.translationdirectory.com (Retrieved on 13 May, 2015).

Al-Najjar, Alaadeen. (2011). Challenges that novice translators encounter in translating contracts and agreements in Jordan. MA Thesis, Middle East University, Amman, Jordan.

Baker, Mona. (1992). In Other Words. (2nd ed.). London: Routledge.

Campbell, Stuart. (1998). Translation into the Second Language. New York: Longman.

Colina, Sonia. (1999). 'Transfer and unwarranted transcoding in the acquisition of translational competence: An empirical investigation'. In Jeroen Vandaele (ed.), Translation and the (Re) location of Meaning, 375-391. Leuven: CETRA.

Colina, Sonia. (2003). Translation Teaching from Research to the Classroom: A Handbook for Teachers. New York: MCGraw Hill.

Darwish, Ali. (1999). Transmetrics: A Formative Approach to Translator Competence Assessment and Translation Quality Evaluation for the New Millennium. Victoria: RMIT University.

Dreyfus, Hubert and Stuart Dreyfus. (1986). Mind over Machine. New York: Free Press.

Harris, Brian and Bianca Sherwood. (1978). 'Translating as an innate skill'. In David Gerver and Wallace Sinaiko (eds.), Language, Interpretation and Communication, 155-170. New York: Plenum.

Hewson, Lance. (2011). An Approach to Translation Criticism. Amsterdam: John Benjamins.

Hidayat, Muhamad. (2013). Self, peer and teacher assessment in translation course.

http://www.file.upi.edu/.../self\%20peer\%20and\%20teacher\%20a (Retrieved on 23 May, 2014).

House, Juliane. (2001). 'Translation quality assessment: Linguistic description versus social evaluation'. Meta, 46 (2): 243-257.

Hurtado-Albir, Amparo and Nicole Martinez Melis. (2001). 'Assessment in translation studies: Research needs'. Meta, 46 (2): 272-287.

Kiraly, Donald. (1995). Pathways to Translation. Kent: The Kent University Press.

Koby, Geoffrey. (2014). 'The ATA flowchart and framework as a differentiated error-marking scale in translation teaching'. In Ying Cui and Wei Zhao (eds.), Handbook of Research on Teaching Methods in Language Translation and Interpretation, 220-253. Hershey: IGI Global. 
Mukatash, Lewis. (2003). 'Towards a new methodology for teaching English to Arab learners'. International Journal of Arabic-English Studies, 4 (1): 211234.

O'Brien, Sharon. (2012). 'Towards a dynamic quality evaluation model for translation'. The Journal of Specialized Translation, 17 (1): 55-77.

Orlando, Marc. (2011). 'Evaluation of translations in the training of professional translators'. The Interpreter and Translator Trainer, 5 (2): 293-308.

PACTE. (2000). 'Acquiring translation competence: Hypotheses and methodological problems of a research project'. In Allison Beeby, Doris Ensinger and Marisa Presas (eds.), Investigating Translation, 99-106. Amsterdam: John Benjamins,

PACTE. (2003). 'Building a translation competence model'. In Fabio Alves (ed.), Triangulating Translation: Perspectives in Process-Oriented Research, 4366. Amsterdam: John Benjamins.

PACTE. (2005). 'Processes and pathways in translation and interpretation'. Meta, 50 (2): 609- 619.

PACTE. (2009). 'Results of the validation of the PACTE translation competence model: Acceptability and decision making'. Across Languages and Cultures, 10 (2): 207-230.

PACTE. (2011). 'Results of the validation of the PACTE translation competence model: Translation project and dynamic translation index'. In Sharon O'Brien (ed.), Cognitive Explorations of Translation, 30-53. London: Continuum.

Pavlovic, Tanja. (2013). 'Exploring directionality in translation studies'. Exploration in English language and linguistics, 1 (2): 149-165.

Prieto-Ramos, Fernando. (2011). 'Developing legal translation competence: An integrative process-oriented approach'. Comparative Legilinguistics, 5 (1): $7-21$.

Riazi, Abdolmehdi and Zahra Davoodi. (2008). On the test methods and translation criteria used to assess Iranian Students' translations in translation courses.

http://www.translationdirectory.com/articles/article1574 (Retrieved on 17 March 2013).

Robinson, Bryan, Clara Rodriguez and Maria Sanchez. (2006).

'Self-assessment in translator training'. Perspectives: Studies in Translatology, 14 (2): 115-138.

Sanchez, Catalina. (2007). Proficiency guidelines to determine levels of communicative translation competence in translation training. MA Thesis, The National University of Costa Rica, Costa Rica, Central America.

Schaeffner, Christina and Beverly Adab. (2000). 'Introduction'. In Christina Schaeffner and Beverly Adab (eds.), Developing Translation Competence, vii-xvi. Amsterdam: John Benjamins,

Stansfield, Charles, Mary Scott and Dorry Kenyon. (1992). 'The measurement of translation ability'. The Modern Language Journal, 76 (4): 455-467. 
Waddington, Christopher. (2001). 'Different methods of evaluating student translations: The question of validity'. Meta, 46 (2):-325.

Yousef, Tawfiq. (2004). 'Translation programmes at Jordanian universities'. Dirasat, 31 (1): 255-265.

\section{Appendix (1) Source text}

Translate the following text into English:

وثيقة تأمين الحو ادث الثخصية

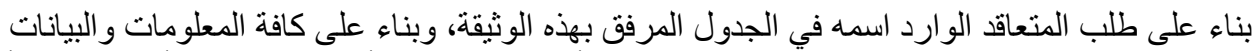

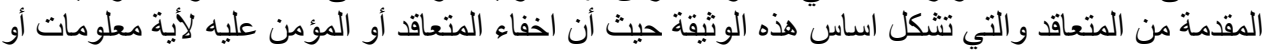

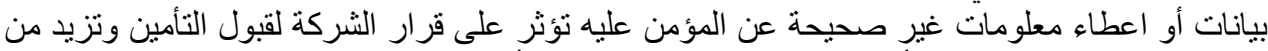

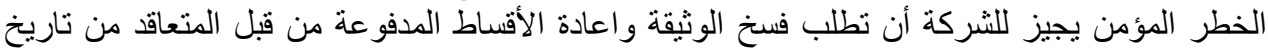

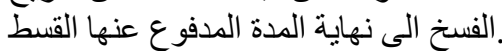

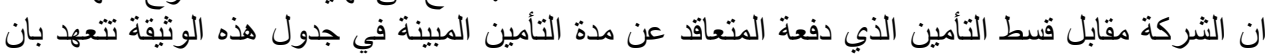

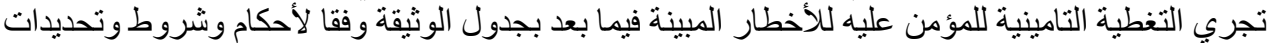

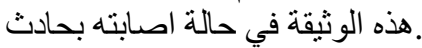

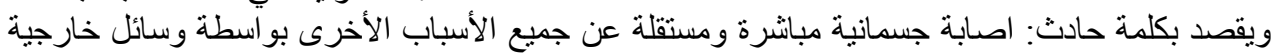

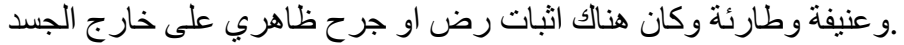

Thank You 


\section{Appendix (2) Self-assessment form}

Dear student,

Appreciate if you could circle $(\boldsymbol{a}, \boldsymbol{b}, \boldsymbol{c}, \boldsymbol{d}, \boldsymbol{e}$ or $\boldsymbol{f})$ in each column; $(1,2,3)$ what better reflects your perspective of the quality of your translated text.

\begin{tabular}{|c|c|c|c|c|c|}
\hline 1. & Content & 2. & $\begin{array}{l}\text { Register, Vocabulary, } \\
\text { Terminology }\end{array}$ & 3. & Written expressions \\
\hline $\mathrm{a}$ & $\begin{array}{l}\text { The text fails to } \\
\text { meet the } \\
\text { minimum } \\
\text { requirements( due } \\
\text { to comprehension } \\
\text { issues). }\end{array}$ & $\mathrm{a}$ & $\begin{array}{l}\text { The text fails to meet } \\
\text { the minimum } \\
\text { requirements (in terms } \\
\text { of register, vocabulary } \\
\text { and terminology. }\end{array}$ & $\mathrm{a}$ & $\begin{array}{l}\text { The text fails to } \\
\text { meet the minimum } \\
\text { requirements (in } \\
\text { terms of structure). }\end{array}$ \\
\hline $\mathrm{b}$ & $\begin{array}{l}\text { My comprehension } \\
\text { of the source text } \\
\text { was limited. }\end{array}$ & $\mathrm{b}$ & $\begin{array}{l}\text { My choice of register } \\
\text { is inappropriate and } \\
\text { inconsistent. } \\
\text { choice of the } \\
\text { vocabulary is limited } \\
\text { with some basic errors. } \\
\text { I am not quite aware of } \\
\text { the appropriate } \\
\text { terminology for this } \\
\text { type of texts (legal). }\end{array}$ & $\mathrm{b}$ & $\begin{array}{l}\text { The way the } \\
\text { expressions are } \\
\text { structured is limited } \\
\text { as there are errors } \\
\text { in the basic } \\
\text { structures of my } \\
\text { translated text. }\end{array}$ \\
\hline $\mathrm{c}$ & $\begin{array}{l}\text { My comprehension } \\
\text { of the source text } \\
\text { was adequate. }\end{array}$ & $\mathrm{c}$ & $\begin{array}{l}\text { My choice of register } \\
\text { is occasionally } \\
\text { inappropriate or } \\
\text { inconsistent. There are } \\
\text { occasional mistakes of } \\
\text { basic vocabulary. I am } \\
\text { aware of the } \\
\text { appropriate } \\
\text { terminology for this } \\
\text { type of texts (legal) } \\
\text { but there are some } \\
\text { errors. }\end{array}$ & $\mathrm{c}$ & $\begin{array}{l}\text { The way the } \\
\text { expressions are } \\
\text { structured is not } \\
\text { effective; there are } \\
\text { errors in the } \\
\text { complex structures } \\
\text { and mistakes in the } \\
\text { basic structures. }\end{array}$ \\
\hline
\end{tabular}




\begin{tabular}{|c|c|c|c|c|c|}
\hline d & $\begin{array}{l}\text { My comprehension } \\
\text { of the source text } \\
\text { was good. }\end{array}$ & $\mathrm{d}$ & $\begin{array}{l}\text { My choice of the } \\
\text { register is mostly } \\
\text { appropriate for this } \\
\text { type of texts (legal) } \\
\text { and mostly consistent } \\
\text { throughout } \\
\text { translation. } \\
\text { My choice of the } \\
\text { vocabulary is effective } \\
\text { despite some mistakes } \\
\text { and my choice of } \\
\text { terminology is } \\
\text { appropriate despite } \\
\text { some occasional errors. }\end{array}$ & $\mathrm{d}$ & $\begin{array}{l}\text { The way the } \\
\text { expressions are } \\
\text { structured is } \\
\text { effective but there } \\
\text { are errors in the use } \\
\text { of articles, } \\
\text { prepositions or } \\
\text { spelling of less } \\
\text { common words in } \\
\text { addition to some } \\
\text { occasional mistakes } \\
\text { in complex } \\
\text { structures. }\end{array}$ \\
\hline $\mathrm{e}$ & $\begin{array}{l}\text { My comprehension } \\
\text { of the source text } \\
\text { was very good. }\end{array}$ & $\mathrm{e}$ & $\begin{array}{l}\text { My choice of the } \\
\text { register is appropriate } \\
\text { for this type of texts } \\
\text { (legal) and consistent } \\
\text { throughout } \\
\text { translation. } \\
\text { My choice of } \\
\text { vocabulary is effective } \\
\text { despiter some } \\
\text { occasional mistakes. } \\
\text { My choice } \\
\text { terminology } \\
\text { appropriate respite } \\
\text { mistakes }\end{array}$ & $\mathrm{e}$ & $\begin{array}{l}\text { The way the } \\
\text { expressions are } \\
\text { structured is good } \\
\text { and effective; } \\
\text { however there are } \\
\text { occasional errors of } \\
\text { advanced usage } \\
\text { only. } \\
\text { My translated text } \\
\text { is almost mistake- } \\
\text { free. }\end{array}$ \\
\hline $\mathrm{f}$ & $\begin{array}{l}\text { My comprehension } \\
\text { of the source text } \\
\text { was excellent. }\end{array}$ & $\mathrm{f}$ & $\begin{array}{l}\text { My choice of the } \\
\text { register is consistently } \\
\text { effective and } \\
\text { appropriate for this } \\
\text { type of texts (legal) } \\
\text { and my choice of } \\
\text { vocabulary is highly } \\
\text { effective and } \\
\text { sophisticated. My } \\
\text { choice of terminology } \\
\text { is appropriate and } \\
\text { wholly accurate. }\end{array}$ & $\mathrm{f}$ & $\begin{array}{l}\text { The way the } \\
\text { expressions are } \\
\text { structured is } \\
\text { sophisticated } \\
\text { without any errors. } \\
\text { My translation is } \\
\text { almost mistake- } \\
\text { free. }\end{array}$ \\
\hline
\end{tabular}

Based on your translation, do you believe the prospective employer would accept to employ you?
A) Yes
B) No
C) I don't know/ Not sure 


\section{Appendix (3) Teachers' assessment form}

Dear Instructor,

1. Based on the translation given (text B) to the Source text (text A), how would you rate the overall quality of the translation?
A) Excellent
B) Very Good
C) Good
D) Acceptable
E) Poor

2. According to your method of assessment, how would you mark the translated text out of $\underline{\mathbf{1 0}}$ ?
A) $8-10$
B) $5-7$
C) Below 5 (Fail Mark)

3. Appreciate if you could elaborate more on your assessment method and/or grading criteria; e.g. the weight given to the choice of terminology, the structure, orientation to target text type, etc.

4. Which errors in this translated text are considered the most serious/ crucial? Exemplify, please.

\begin{tabular}{|l|l|}
\hline Type of Error & Example \\
\hline 1. & 1. \\
\hline 2. & 2. \\
\hline 3. & 3. \\
\hline 4. & 4. \\
\hline
\end{tabular}

Thank you 


\section{Appendix (4) Employers' assessment form}

Dear Assessor,

1. Based on the translation given (text B) to the Source text (text A), how would you rate the overall quality of the translation?
A) Excellent
B) Very Good
C) Good
D) Acceptable
E) Poor

2. If this translation was provided by an applicant at your company, would you accept him/her for the job of a translator?
A) YES
B) $\mathrm{NO}$

3. According to your method of assessment, how would you mark the translated text out of $\underline{\mathbf{1 0}}$ ?
A) $8-10$
B) $5-7$
C) Below 5 (Fail Mark)

4. Appreciate if you could elaborate more on your assessment method and/or grading criteria; e.g., the weight given to the choice of terminology, the structure, orientation to target text type, etc.

5. Which errors in this translated text are considered the most serious/ crucial? Exemplify, please.

\begin{tabular}{|l|l|}
\hline Type of Error & Example \\
\hline 1. & 1. \\
\hline 2. & 2. \\
\hline 3. & 3. \\
\hline 4. & 4. \\
\hline
\end{tabular}

Thank you 